\title{
'So you want to be an orthodontist'
}

$\mathrm{T}$ he annual 'So you want to be an orthodontist' meeting was held in London at the British Orthodontic Society's (BOS') headquarters in Central London on 24 November 2017.

Organised by the BOS Training Grades Group, the day featured a busy programme with talks from speakers with a variety of backgrounds and experience. Ms Helen Tippet gave a detailed insight into the national recruitment process from the perspective of an orthodontic consultant which was added to by orthodontic registrar Mr Robert Smythe who outlined his experience of the process from a candidate's perspective. This was an informative introduction to both the application form and interview stations and helped answer many of the delegates' questions about what to expect from the day.

Further understanding of orthodontic training was gained from Professor Susan Cunningham who gave an overview of the various training programmes as well as the importance of the research component of orthodontic registrar training. This helped to highlight the prospect of further academic study and the application of research completed during specialist training in future clinical orthodontic practice.
A career in orthodontics after completion of specialist training was described by orthodontic specialist Mr Neil Patel and post-CCST StR5 Dr Eileen Watt. This overview of career prospects in both specialist practice and hospital settings was well received by all delegates. I found this especially useful to understand the wider career options and possibilities for future training.

Due to the competitive nature of applications to specialist training, advice on building a strong CV was given by Mr Sadaf Khan. This session gave excellent advice and practical tips for delegates at all stages of preparation for their application.

Round table discussions were held in the afternoon and these were the perfect opportunity for informal networking and delegates took the chance to ask the speakers questions about the talks earlier in the day. Examples of previous candidates' portfolios and cases presented at the MOrth examinations were available for delegates to look over. Delegates also had the time to seek advice on their own applications from the speakers.

Overall the day was an excellent overview of a career in orthodontics and has undoubtedly inspired many delegates including myself to apply to specialist training this year and beyond. I would suggest this in

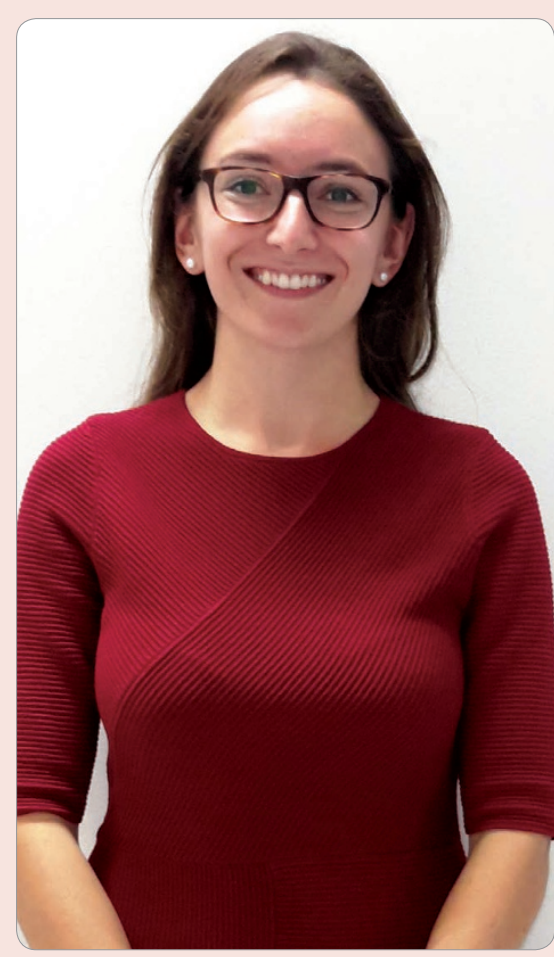

Libby Richardson, attendee at this year's 'So your want to be an orthodontist' meeting

an invaluable event to attend for anyone interested in specialist orthodontic training and I wish to thank the organisers for coordinating this meeting.

By Libby Richardson,

DCT2 in paediatric dentistry, Great Ormond Street Hospital

\section{Society news}

The Royal College of Surgeons of Edinburgh The RCSEd has announced that, following negotiations between the College's Trainees' Committee and HM Revenue \& Customs (HMRC), the College has been successful in obtaining agreement for trainees in the ten surgical specialties to claim tax relief on the examination fee for the Specialty Fellowship Examinations (FRCS).

\section{Faculty of General Dental Practice (UK)} FGDP(UK)'s Selection criteria for dental radiography, a leading text on indications for radiographic investigation in dentistry, is to be updated in light of updated regulations on the use of ionising radiation.
The current third (2013) edition will be amended to take into account the recently-published Ionising Radiation Regulations 2017 (IRR17), and the Ionising Radiation (Medical Exposure) Regulations 2018 (IRMER18), and the changes will be reflected in both the online and book versions of the guidance.

IRR17 replaced IRR99 on 1 January 2018, and IRMER 18 replaced boththe original IRMER 2000 and the amendments from 2006 and 2011 on 6 February 2018. Both apply in England, Scotland and Wales, and separate regulations will be produced later for Northern Ireland.

\section{British Society for Oral and Dental Research}

The BSODR is hosting another Early Career Researchers Workshop which will be held on Wednesday 28 March 2018 at the Dental School, University of Glasgow, from 10 am to $4 \mathrm{pm}$.

The workshop is entitled 'How to obtain research grant funding' and will consider various aspects and perspectives of the process of writing research grants and obtaining funding.

Registration is free and open to all IADR/ BSODR members only, and will open soon. Lunch and refreshments will be provided. http://www.bsodr.org.uk. 